\title{
A tool for detecting crop water status using airborne high-resolution thermal imagery
}

\author{
J. Bellvert ${ }^{1}$, P. J. Zarco-Tejada ${ }^{2}$, J. Girona ${ }^{1}$, \\ V. González-Dugo ${ }^{2} \&$ E. Fereres ${ }^{2,3}$ \\ ${ }^{1}$ Efficient Use of Water program, \\ Institute of Research, Technology, Food and Agriculture (IRTA), Spain \\ ${ }^{2}$ Institute for Sustainable Agriculture (IAS), \\ Consejo Superior de Investigaciones Cientificas (CSIC), Spain \\ ${ }^{3}$ Department of Agronomy, University of Córdoba (UCO), Spain
}

\begin{abstract}
Knowledge on crop water status at the orchard scale is necessary for the efficient management of irrigation water. Canopy temperature has long been recognized as a plant water status indicator, and crop water stress index (CWSI), which is obtained from canopy temperature could be used as a tool for remotely detecting plant water status from airborne high-resolution thermal imagery. In 2012, CWSI baselines for olive and peach trees were derived from infrared thermometer data. An aircraft equipped with a thermal sensor flew over two orchards acquiring highresolution thermal images. At the same time, leaf water potential $\left(\Psi_{L}\right)$ was measured in eighteen trees per specie. Relationship between the difference of canopy and air temperature $\left(T_{c}-T_{a}\right)$ and $\Psi_{L}$ had a $\mathrm{R}^{2}$ of 0.74 and 0.82 , for peach and olive, respectively. CWSI ranged from zero to one and showed a significant correlation with $\Psi_{L}$. Maps of estimated $\Psi_{L}$ (derived from CWSI - $\Psi_{\mathrm{L}}$ relationships) were able to detect the spatial variability of plant water status within the orchards, and may be a feasible tool for irrigation purposes.
\end{abstract}

Keywords: remote sensing, leaf water potential, crop water status, crop water stress index. 


\section{Introduction}

Adequate irrigation management is required for an efficient and profitable use of water in irrigation of agricultural crops. Spatial variability in water requirements across a field affects the efficient use of irrigation water. Identifying and mapping spatial variability based on plant water status (leaf water potential, $\Psi_{L}$ ) may be of interest for managing irrigation (Bellvert et al. [1]).

The recent advances in remote sensing offer the possibility of its use for water management applications over large areas. The established method for detecting remotely crop water status is through the measurement of a crop's surface temperature $[2,3]$. An approach for quantifying water stress is by using the so called 'Crop Water Stress Index' (CWSI) [4, 5]. Many studies have shown good correlations between CWSI and midday $\Psi_{L}$ in woody crops. Examples are Möller et al. [6] in grapevines, Testi et al. [7] in pistachio trees, or Ben-Gal et al. [8] in olive trees. However, only Bellvert et al. [9] related $\Psi_{L}$ with CWSI by using highresolution remote sensing imagery at vineyard scale.

To obtain estimated $\Psi_{L}$ maps from remotely sensed CWSI may be useful for assessing the spatial variability in water stress across orchards. The specific aim for this study was to compare the CWSI derived from airborne thermal imagery and $\Psi_{L}$ in peach and olive trees, and to explore the feasibility of mapping crop stress by high-resolution thermal imagery.

\section{Materials and methods}

The study was carried out in 2012 and 2013 at two commercial orchards located near Lleida, Spain. A 2-ha orchard $\left(41^{\circ} 41^{\prime} 38 \mathrm{~N}, 0^{\circ} 32^{\prime} 54 \mathrm{E}\right)$ was planted in 1996 with an early maturing cultivar of peach (Prunus persica L. cv. Royal Glory) in a $3 \mathrm{~m} \mathrm{x} 4 \mathrm{~m}$ grid. The second study site was an 8-ha olive orchard (Olea europaea L. $c v$. Arbequina) of eleven years old in a $5 \mathrm{~m} \mathrm{x} 3 \mathrm{~m}$ grid $\left(41^{\circ} 40^{\prime} 57 \mathrm{~N}, 0^{\circ} 32^{\prime} 00 \mathrm{E}\right)$.

Three irrigation treatments were set up under different levels of water status. The treatments were: i) full-irrigation control, where irrigation replaced $100 \%$ ETc, and ii) moderate deficit irrigation, where irrigation replaces 50\% ETc, iii) deficit irrigation, where water was applied only after midday leaf water potential dropped below -2.0 MPa and -3.0 MPa in peach and olive trees, respectively.

Infrared temperature sensors were installed above full-irrigation control olive and peach trees. Non-water-stressed baselines (NWSB) were obtained from the relationship between $T_{c}-T_{a}$ and vapour pressure deficit (VPD). The empirical crop water stress index (CWSI) was calculated as [4]:

$$
C W S I=\frac{\left(T_{c}-T_{a}\right)-\left(T_{c}-T_{a}\right)_{L L}}{\left(T_{c}-T_{a}\right)_{U L}-\left(T_{c}-T_{a}\right)_{L L}}
$$

where $T_{c}-T_{a}$ is measured canopy-air temperature difference; $\left(T_{c}-T_{a}\right)_{L L}$ lower limit of $\left(T_{c}-T_{a}\right)$ of a canopy which is transpiring at the potential rate, and $\left(T_{c}-T_{a}\right)_{U L}$ expected differential in the case of a non-transpiring canopy. $\left(T_{c}-T_{a}\right)_{L L}$ was 
calculated from the minimum $T_{c}-T_{a}$ values for each VPD, according to [2]. $\left(T_{c}-T_{a}\right)_{U L}$ is function of the non-water-stressed baseline (NWSB) corrected by $T_{a}$. Only data from 10:00 to 16:00 hours (solar time), on sunny days and with windspeed below $6 \mathrm{~m} \mathrm{~s}^{-1}$ (at a height of $10 \mathrm{~m}$ ) were used in the assessment of CWSI.

In 2012, a flight was conducted with a thermal sensor (FLIR SC655, FLIR Systems, USA) installed on an aircraft (CESSNA C172S EC-JYN). The camera had a resolution of $640 \times 480$ pixels, equipped with a $24.5 \mathrm{~mm} \mathrm{f1.0} \mathrm{lens,} \mathrm{connected}$ to a computer via USB 2.0 protocol. The spectral response was in the range of $7.5-13 \mu \mathrm{m}$. The flight was conducted at 12:00 solar time (14:00 local time) on 15 June 2012 at $150 \mathrm{~m}$ altitude above the ground level. It delivers a ground resolution of $0.3 \mathrm{~m}$. The use of high-resolution thermal images enables to discriminate pure canopy vegetation pixels from soil background effects (fig. 1). In 2013, a flight was conducted over the 2-ha peach orchard and leaf water potential was estimated according to results obtained in the previous year. Air temperature $\left(T_{a}\right)$ and vapour pressure deficit (VPD) at flight time were $32.1^{\circ} \mathrm{C}$ and $3.44 \mathrm{KPa}$, respectively. Concomitant with the flight, leaf water potential $\left(\Psi_{L}\right)$ was measured in eighteen trees and grapevines (six per irrigation treatment). Two fully expanded leaves exposed to direct sunlight were measured on each vine. A Scholander pressure chamber (Soil Moisture Equipment Corp., Santa Barbara, CA, USA) was used following the recommendations of Turner and Long [10].

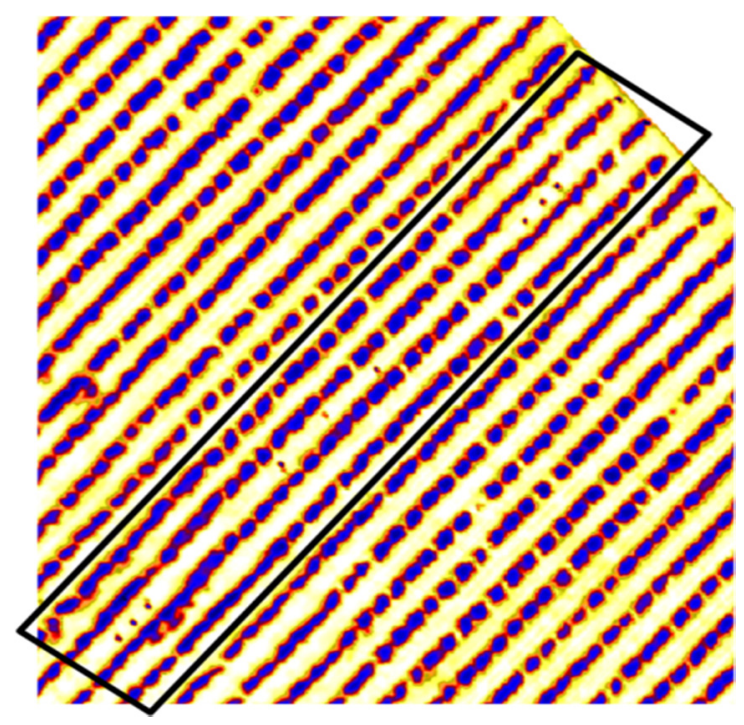

Figure 1: Thermal imagery of the olive orchard studied area (rectangle) obtained with an airborne platform at $150-\mathrm{m}$ altitude. Spatial resolution was $0.3 \mathrm{~m}$ enabling the capture of only pure canopy and excluding soil, background targets and shadows. 


\section{Results and discussion}

The non-water-stressed baselines (NWSB) were obtained from the relationship between $T_{c}-T_{a}$ and vapour pressure deficit (VPD). Only data from 10.00 to 16.00 $\mathrm{h}$ (solar time) was used for this relationship. As VPD increased, $T_{c}-T_{a}$ values were more negative. NWSB and $\left(T_{c}-T_{a}\right)_{L L}$ respectively were $0.13 * \mathrm{VPD}^{2}$ $2.32 * \mathrm{VPD}+4.51$ and $-1.56 * \mathrm{VPD}+1.99$ for peach, and $0.12 * \mathrm{VPD}^{2}$ $1.72 * \mathrm{VPD}+4.45$ and $-2.05 * \mathrm{VPD}+3.97$ for olive trees. CWSI was calculated according with equation (1), rendering values ranging from zero to one, which respectively corresponded with maximum transpiration and complete stomatal closure, respectively.

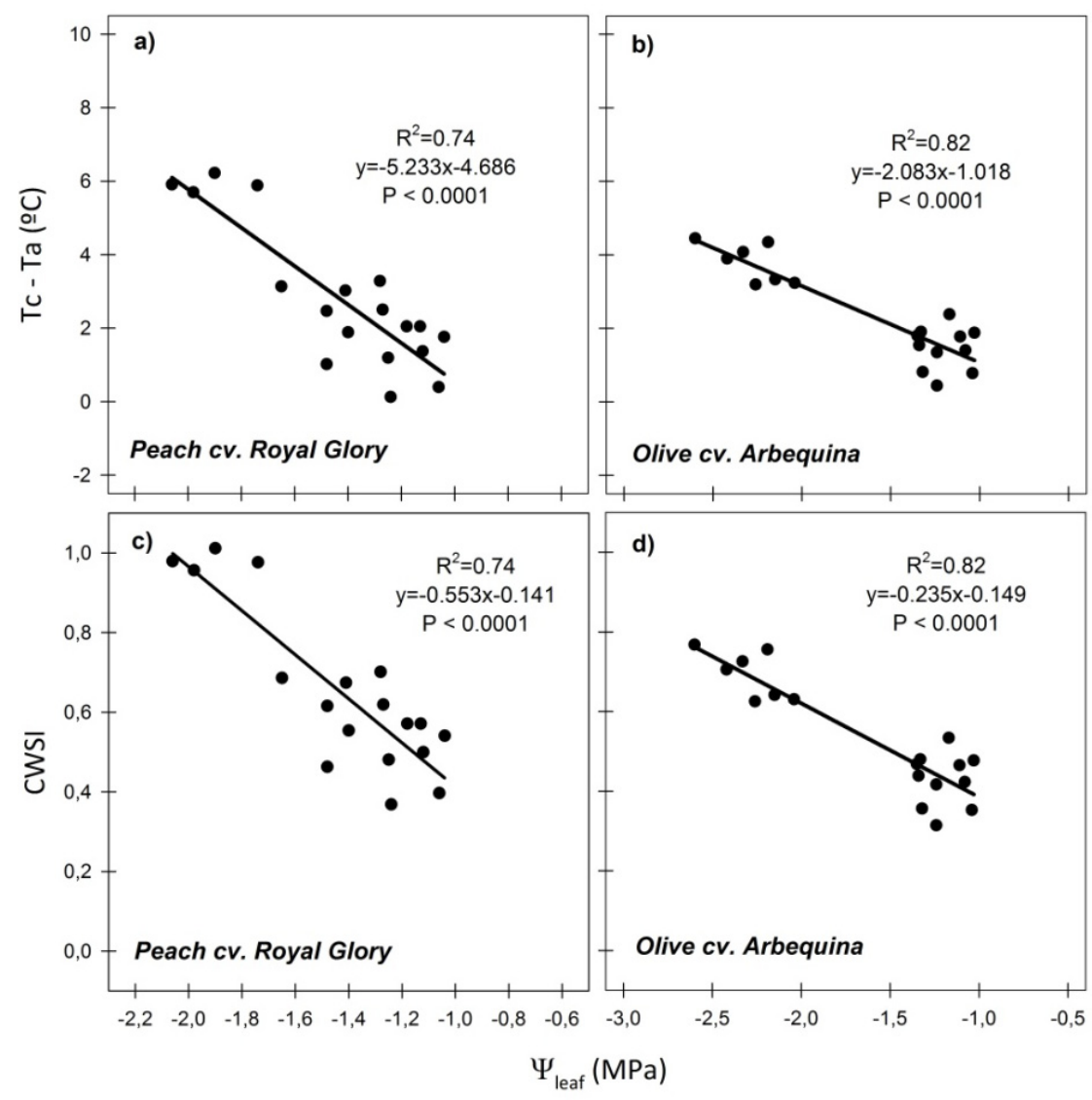

Figure 2: Relationships between leaf water potential $\left(\Psi_{L}\right)$ and $T_{c}-T_{a}$ and CWSI in peach $(\mathrm{a}, \mathrm{c})$ and olive trees $(\mathrm{b}, \mathrm{d})$ on 15 June 2012. Leaf temperature $\left(T_{c}\right)$ and CWSI estimates were obtained from airborne thermal sensor imagery. 
Relationships between difference of crop and air temperature $\left(T_{c}-T_{a}\right)$ and leaf water potential $\left(\Psi_{L}\right)$ were significant $(\mathrm{p}<0.0001)$ for both crops. In peaches, maximum leaf temperature $\left(T_{c}\right)$ reached $6^{\circ} \mathrm{C}$ above $T_{a}$, when $\Psi_{L}$ reached -2.15 $\mathrm{MPa}$. That $\Psi_{L}$ corresponded with complete stomatal closure and CWSI values were one. On the other hand, well-watered peach trees had $\Psi_{L}$ values above -1.2 $\mathrm{MPa}$, corresponding with CWSI values of 0.35 . In olive trees, maximum measured values of $T_{c}-T_{a}$ reached $4.2^{\circ} \mathrm{C}$. These maximum values corresponded with a CWSI of 0.78 . The minimum value of $-2.7 \mathrm{MPa}$ for olive trees was only half way of the estimates corresponding to $\mathrm{CWSI}=1$ which was $-4.88 \mathrm{MPa}$ (fig. $2 \mathrm{~d}$ ).

The linear relationships between CWSI and $\Psi_{L}$ may be used for the remotely estimation of $\Psi_{L}$ and a feasible tool for detecting spatial variability of plant water status within an orchard. $\Psi_{L}$ is the most straightforward indicator of plant water stress and, hence, a stress indicator for triggering irrigation [11]. Estimation of leaf water potential $\left(\Psi_{e s t}\right)$ from remotely sensed canopy temperature may be a feasible tool for irrigation scheduling purposes in peach and olive trees, as already has been demonstrated for grapevines [9]. If thermal imagery has to be useful for irrigation it should first define the optimal $\Psi_{L}$ thresholds at each phenological moment to trigger the onset of an irrigation event. By estimating averaged $\Psi_{\text {est }}$ of each irrigation sector of the orchard, irrigation could be scheduled differently according to crop water status, and applied different amounts of water in accordance with individual water requirements. Fig. 3 illustrates a detailed map of 2-ha peach orchard indicating the averaged $\Psi_{\text {est }}$ values for each irrigation sector. In this example, spatial variability of crop water status within the orchard ranged from -2.00 to $-0.90 \mathrm{MPa}$. The most stressed irrigation sectors had averaged $\Psi_{\text {est }}$ values of -1.40 and $-1.46 \mathrm{MPa}$, while the well-watered zones had an averaged $\Psi_{\text {est }}$ of $-1.14 \mathrm{MPa}$. This information may be useful for technicians, who will have the capacity to irrigate precisely according to the principle of precision agriculture, and apply more irrigation in those sectors under deficit, and less water in that sectors with an adequate crop water status. This precise irrigation may improve water distribution within the orchard, help reach uniform yield, and consequently, important water savings.

The work presented here was carried out with information from one specific day. However, the existence of differential leaf conductance sensitivity to $\Psi_{\mathrm{L}}$ throughout the season [12] implies that phenological relationships should also be determined in further studies.

\section{Conclusions}

High-resolution airborne thermal imagery can improve the accuracy of remote CWSI determination and provides precise information of crop water status of peach and olive trees. Remotely sensed CWSI has been successfully related with leaf water potential, and being able to produce high-resolution maps of $\Psi_{\text {est }}$. These maps can be used for irrigation scheduling purposes. Therefore, this tool is presented as a promising and powerful method for assessing plant water stress in heterogeneous crops, especially in arid or semi-arid climates. 


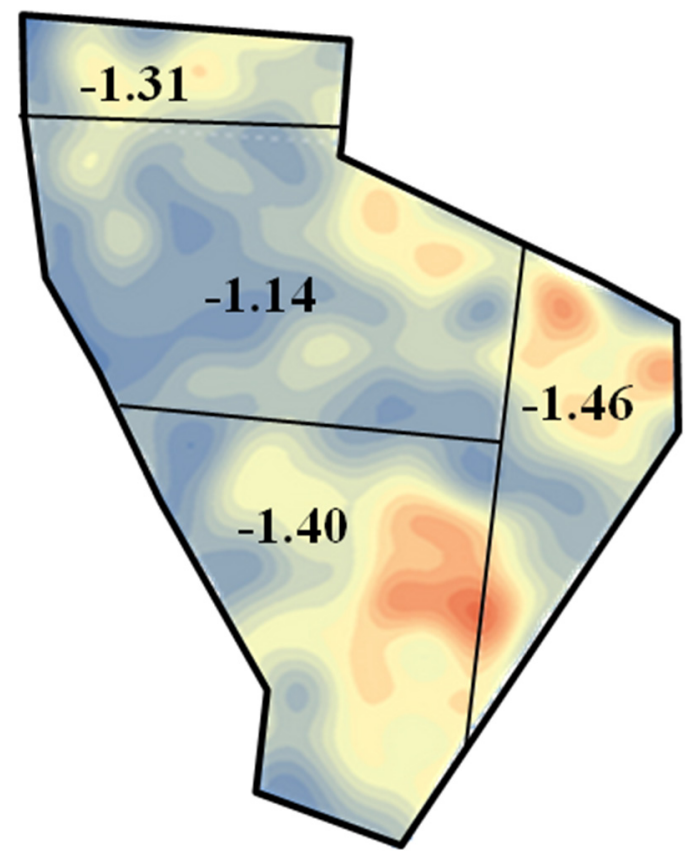

\section{$\Psi_{\text {est }}(\mathrm{MPa})$}

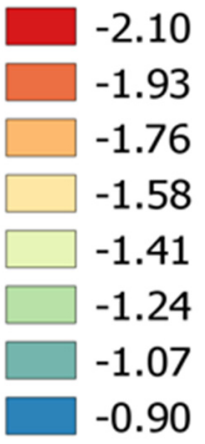

Figure 3: Peach orchard map of remotely sensed estimated leaf water potential $\left(\Psi_{e s t}\right)$, obtained from airborne thermal imagery.

\section{Acknowledgements}

This work received partial financial support from the Spanish Ministry of Science and Innovation (MCI) for the project INNPACTO IPT-2011-1786-060000. We are grateful for the opportunity to carry out this study under the research agreement between CODORNIU, SORIGUÉ, IRTA and IAS-CSIC. The authors thank the team of Quantalab, IAS-CSIC of Córdoba for the technical support in field airborne flights and image processing, and also the team of Efficient Use of Water of IRTA for their support in the field campaign.

\section{References}

[1] Bellvert, J., Marsal, J., Mata, M., \& Girona, J., Identifying irrigation zones across a 7.5-ha 'Pinot noir' vineyard based on the variability of vine water status and multispectral images. Irrigation Science, 30, pp. 499-509, 2012.

[2] Tanner, C. B., Plant temperatures. Agronomy Journal, 55, pp. 210-211, 1963.

[3] Fuchs, M., \& Tanner, C. B., Infrared thermometry of vegetation. Agronomy Journal, 58, pp. 297-601, 1966. 
[4] Idso, S. B., Jackson, R. D., Pinter, P. J., Reginato, R. J., \& Hatfield, J. L., Normalizing the stress degree day parameter for environmental variability. Agricultural Meteorology, 24, pp. 45-55,1981.

[5] Jackson, R. D., Idso, S., Reginato, R., \& Pinter, P, Jr., Canopy temperature as a crop water stress index indicator. Water Resources Research, 17, pp. 1133-1138, 1981.

[6] Möller, M., Alchanatis, V., Cohen, Y., Meron, M., Tsipris, J., Naor, A., Ostrovsky, V., Sprintsin, M., \& Cohen, S., Use of thermal and visible imagery for estimating crop water status of irrigated grapevine. J. Exp. Bot. 58, pp. 827-838, 2007.

[7] Testi, L., Goldhamer, D. A., Iniesta, F., \& Salinas, M., Crop water stress index is a sensitive water stress indicator in pistachio trees. Irrigation Science, 26, pp. 395-405, 2008.

[8] Ben-Gal, A., Agam, N., Alchanatis, V., Cohen, Y., Yermiyahu, U., Zipori, I., Presnov, E., Sprintsin, M., \& Dag, A., Evaluating water stress in irrigated olives: correlation of soil water status, tree water status, and thermal imagery. Irrigation Science, 27, pp. 367-376, 2009.

[9] Bellvert, J., Zarco-Tejada, P.J., Fereres, E., \& Girona, J., Mapping crop water stress index in a 'Pinot-noir' vineyard: comparing ground measurements with thermal remote sensing imagery from an unmanned aerial vehicle. Precision Agriculture Journal, DOI 10.1007/s11119-0139334-5, pp. 1385-2256, 2013.

[10] Turner, N. C., \& Long, M. J., Errors arising from rapid water loss in the measurement of leaf water potential by pressure chamber technique. Australian Journal of Plant Physiology, 7, pp. 527-537, 1980.

[11] Girona, J., Mata, M., del Campo, J., Arbonés, A., Bartra, E., \& Marsal, J. The use of midday leaf water potential for scheduling deficit irrigation in vineyards. Irrigation Science, 24, pp. 115-127, 2006.

[12] Marshal, J., \& Girona, J., Relationship between leaf water potential and gas exchange activity at different phenological stages and fruit loads in peach trees. J. Amer. Soc. Hort. Sci. 122, pp. 415-421, 1997. 